\title{
ANALISIS DAYA SAING EKSPOR JASA NEGARA ASEAN
}

\author{
Efrida Tita Nuryana', \\ Slamet Santoso \\ Rochmat Aldy Purnomo \\ Asis Riat Winanto \\ Choirul Hamidah \\ Universitas Muhammadiyah Ponorogo
}

\begin{abstract}
This research aims to determine the export competitiveness of asean country's service sector's. The data used to support this research is secondary data in the form of service sector export data, total exports, and Gross Domestic Product (GDP) Constant Price for the study period in 2015-2019. The analysis tools used are Klassen Typology, Location Quotient (LQ), Revealed Competitive Advantage (RCA), and Overlay analysis. Based on the results of overlay analysis by combining three analytical tools (Klassen Typology, $L Q$, and RCA), shows that the export competitiveness of the service sector owned by Singapore is insurance and pension services; charges for the use of intellectual property; telecommunications, computer, and information services; and other business services. Malaysia's export competitiveness of the service sector is personal, cultural, and recreational services, while the Philippines is telecommunications, computer, and information services. Meanwhile, Indonesia and Vietnam are ASEAN countries that do not have export-competitive service sectors.
\end{abstract}

Keywords: Exports, Competitiveness, Service Sector, ASEAN

\begin{abstract}
ABSTRAK
Penelitian ini bertujuan untuk mengetahui daya saing ekspor sektor jasa negara Asean. Data yang digunakan untuk mendukung penelitian ini adalah data sekunder berupa data ekspor sektor jasa, total ekspor, dan Harga Konstan Produk Domestik Bruto (PDB) periode penelitian tahun 20152019. Alat analisis yang digunakan adalah Klassen Typology, Location Quotient (LQ), Revealed Competitive Advantage (RCA), dan Analisis Overlay. Berdasarkan hasil analisis overlay dengan menggabungkan tiga alat analisis (Klassen Typology, LQ, dan RCA), menunjukkan bahwa daya saing ekspor sektor jasa yang dimiliki Singapura adalah jasa asuransi dan pensiun; biaya untuk penggunaan kekayaan intelektual; telekomunikasi, komputer, dan layanan informasi; dan layanan bisnis lainnya. Daya saing ekspor Malaysia untuk sektor jasa adalah jasa pribadi, budaya, dan rekreasi, sedangkan Filipina adalah jasa telekomunikasi, komputer, dan informasi. Sedangkan Indonesia dan Vietnam merupakan negara ASEAN yang tidak memiliki sektor jasa yang berdaya saing ekspor.
\end{abstract}

Kata kunci: Ekspor, Daya Saing, Sektor Jasa, ASEAN

Klasifikasi JEL: F15; F43

\section{PENDAHULUAN}

Daya saing merupakan sekumpulan institusi, peraturan dan aspek yang memengaruhi tingkat kapasitas produksi suatu negara (Cann, 2016). Konsep daya saing pertama kali dikenalkan oleh David Ricardo. Dikutip dari penelitian yang dilakukan oleh Sa'idy (2013), konsep daya saing yang dijelaskan Ricardo berdasar dari hukum keunggulan komparatif dimana perdagangan masih dapat dilakukan antara dua negara walaupun terdapat negara dengan kerugian mutlak atas negara lain dalam menghasilkan dua produk. Negara dengan kerugian mutlak akan tetap mendapatkan keuntungan dari kegiatan perdagangan jika negara tersebut mengadakan

\footnotetext{
${ }^{1}$ Email: efridatita21@gmail.com
} 


\section{2 | Bina Ekonomi}

spesialisasi produk pada produk dengan kerugian mutlak yang lebih kecil.

Dalam Cetak Biru Masyarakat ekonomi ASEAN yang dirilis pada November 2015 disebutkan bahwa tujuan penandatanganan perjanjian AFAS yaitu mengembangkan dan memperdalam integrasi di dalam ASEAN dan pada rantai persediaan di ranah internasional, baik barang atau jasa, serta memajukan daya saing Negara ASEAN dalam sektor jasa. Sektor jasa yang tangguh dapat memudahkan pengembangan industri, inovasi, dan efisiensi. Sehingga hal tersebut akan mendorong peranan potensial sektor jasa terhadap pembangunan dan pertumbuhan ekonomi (ASEAN Secretariat, 2021).

Sektor jasa merupakan sektor yang berperan penting dalam suatu aktivitas perekonomian, mulai dari layanan dasar hingga layanan infrastruktur. Jasa dapat ditemukan di dalam semua aktivitas ekonomi termasuk aktivitas bisnis di berbagai sektor. Oleh sebab itu, sektor jasa berperan sebagai input antara bagi semua kegiatan perekonomian.

Jasa menjadi komponen yang semakin memegang peranan yang besar dan penting di banyak negara di dunia, termasuk negara di Kawasan ASEAN. Hal tersebut dapat dilihat berdasarkan tingkat produktivitas sektor jasa melalui besaran kontribusinya terhadap Produk Domestik Bruto (PDB) ASEAN. Selama 10 tahun terakhir, jasa menjadi komponen PDB yang dominan dan terus mengalami perkembangan di ekonomi ASEAN. Pada 2019, sektor jasa memberikan kontribusi antara 38\% dan 65\% terhadap PDB Negara Anggota ASEAN dibandingkan dengan sektor pertanian dan industri, dimana mayoritas kontribusinya antara $40 \%$ hingga 60\% (ASEAN Secretariat, 2021).

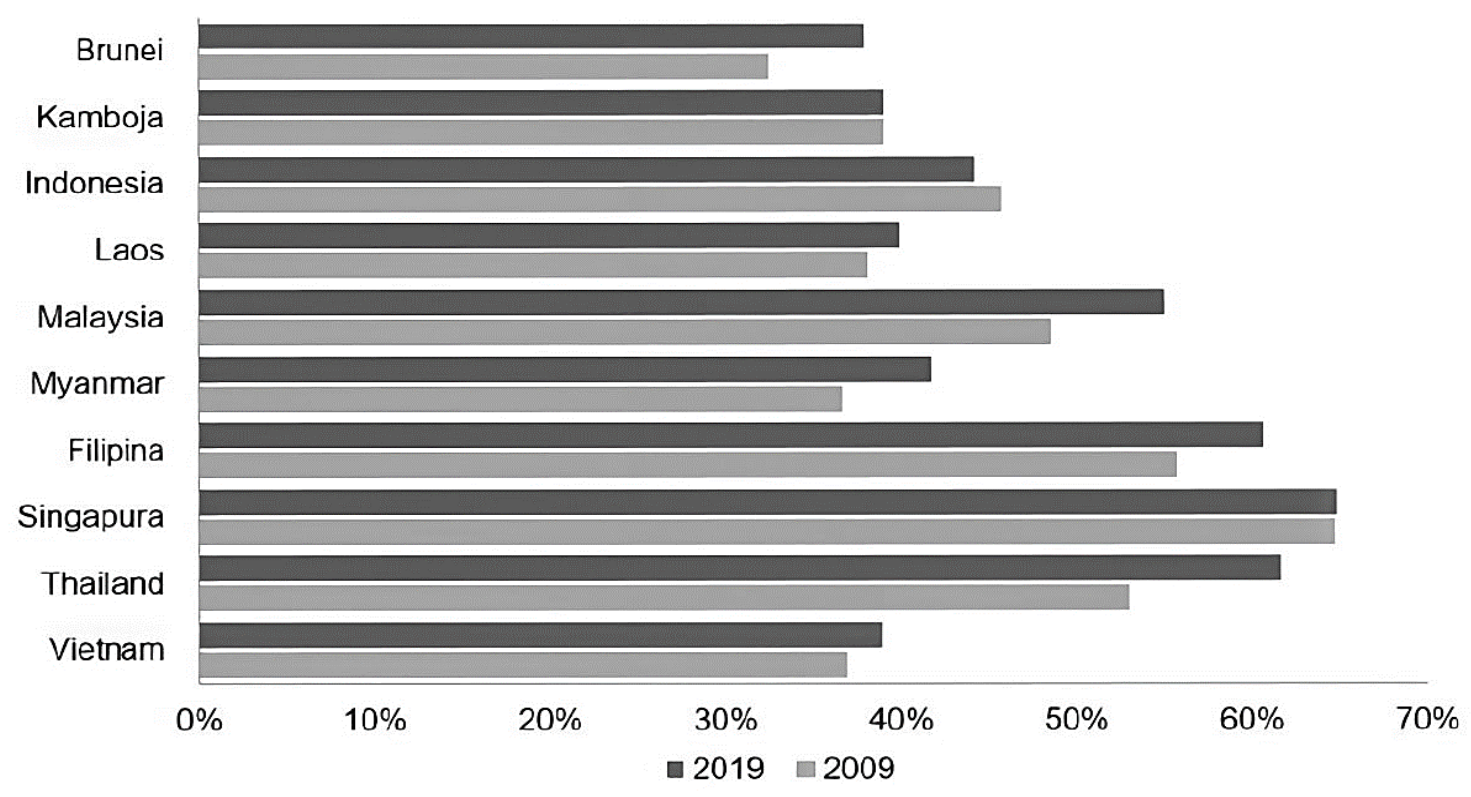

Sumber : ASEAN Secretariat, 2021

\section{Gambar 1. Presentase Kontribusi Sektor Jasa Negara ASEAN Terhadap PDB Tahun 2009 dan 2019}

Menurut data Perdagangan Jasa Berdasarkan Negara Pelapor dan Kategori Jasa Utama yang dimuat di ASEANStats (2020), peningkatan yang signifikan terjadi pada pedagangan jasa ASEAN ke Negara-Negara Tujuan di dunia. Selama periode 2015 hingga 2019, perdagangan jasa Negara ASEAN yang dilakukan ke Negara-Negara tujuan tumbuh dari US\$ 642.151,77 juta pada 2015 menjadi US\$ 844.567,98 juta pada 2019. 


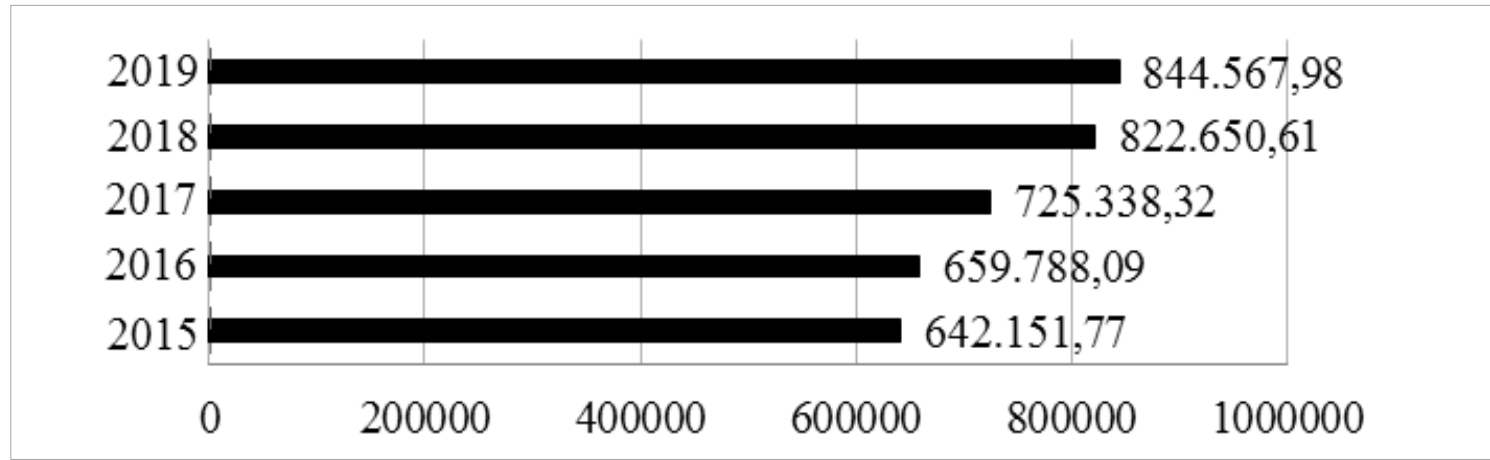

Sumber : ASEANStats

\section{Gambar 2. Perdagangan Jasa ASEAN ke Negara-Negara Tujuan Tahun 2015-2019 (Dalam Juta USD)}

Perdagangan memerankan peran penting sebagai salah satu pilar ekonomi ASEAN, khususnya bidang perdagangan jasa. Ada 12 (dua belas) sektor jasa yang menjadi prioritas dalam AFAS dimana kedua belas sektor tersebut merupakan sektor jasa yang ditetapkan oleh World Trade Organization (WTO). Sektor-sektor jasa tersebut adalah jasa komunikasi; jasa bisnis; jasa distribusi; jasa pendidikan; jasa konstruksi dan teknik terkait; jasa kesehatan dan sosial; jasa lingkungan; jasa keuangan; jasa pariwisata dan perjalanan; jasa transportasi; jasa rekreasi, budaya, dan olahraga; serta jasa lainnya (AEC Council Indonesia, 2019).

ASEAN Framework Agreement on Services (AFAS) merupakan kerja sama sebagai upaya mencapai integrasi ekonomi di kawasan ASEAN khususnya pada bidang jasa guna menambah efisiensi dan daya saing, mendiversifikasi kemampuan produksi, serta penyediaan dan penyaluran jasa dari penyedia jasa setiap negara yang menjadi anggota ASEAN. AFAS juga bertujuan meniadakan kendala-kendala berkaitan dengan perdagangan jasa antaranggota ASEAN dan mewujudkan perdagangan bebas di sektor jasa (ASEAN Secretariat, 2021).

Semakin terbukanya perdagangan yang dilakukan setiap Negara akan mendorong terciptanya arus globalisasi yang semakin cepat. Jusuf Kalla mengatakan dalam forum ASEAN Summit for State Owned Enterprise atau KTT BUMN se-ASEAN yang berlangsung Februari 2015 silam, bahwa kunci dapat bertahan dan menjadi pemenang di persaingan global termasuk pasar MEA adalah kapasitas, efisiensi, dan daya saing (Direktorat Jenderal Kerja Sama ASEAN Kementerian Luar Negeri RI, 2015).

Pada umumnya, negara yang menerapkan sistem perekonomian yang bersifat terbuka sangat mengandalkan ekspor sebagai upaya meningkatkan perekonomian negaranya. Hal tersebut disebabkan karena ekspor dapat memengaruhi laju perekonomian negara. Untuk meningkatkan ekspor dapat melalui optimalisasi sektor yang berpotensi ditawarkan ke luar negeri. Salah satunya yaitu melalui sektor jasa.

Menurut data perdagangaan jasa yang dimuat di ASEANStats, ekspor jasa negara ASEAN ke negara-negara tujuan mengalami kenaikan setiap tahunnya. Tahun 2015, nilai ekspor jasa 


\section{4 | Bina Ekonomi}

ASEAN mencapai US\$319.200,04 juta. Tahun 2016 nilai ekspor jasa ASEAN mengalami kenaikan menjadi US\$337.286,09 juta. Kemudian tahun 2017 dan tahun 2018 nilai ekspor jasa ASEAN juga meningkat, masing-masing sebesar US\$ $370.478,22$ juta dan US $\$ 428.537,92$ juta. Sementara pada tahun 2019, ekspor jasa ASEAN mencapai nilai tertinggi dibandingkan tahun-tahun sebelumnya yaitu sebesar US\$ 444.779,09 juta.

Tabel 1. Nilai Ekspor Jasa Negara ASEAN ke Negara-Negara Tujuan Tahun 20152019 (Dalam Juta USD)

\begin{tabular}{crrrrr}
\hline \multirow{2}{*}{ Negara } & \multicolumn{5}{c}{ Tahun } \\
\cline { 2 - 6 } & \multicolumn{1}{c}{$\mathbf{2 0 1 5}$} & \multicolumn{1}{c}{$\mathbf{2 0 1 6}$} & \multicolumn{1}{c}{$\mathbf{2 0 1 7}$} & \multicolumn{1}{c}{$\mathbf{2 0 1 8}$} & \multicolumn{1}{c}{$\mathbf{2 0 1 9}$} \\
\hline Indonesia & $22.220,87$ & $23.323,54$ & $25.327,65$ & $31.206,85$ & $31.644,78$ \\
Malaysia & $34.847,13$ & $35.582,37$ & $37.057,41$ & $40.240,52$ & $40.988,08$ \\
Filipina & $29.065,05$ & $31.203,61$ & $34.831,65$ & $38.396,81$ & $40.973,57$ \\
Singapura & $153.202,43$ & $151.695,19$ & $169.713,19$ & $202.583,35$ & $204.807,43$ \\
Vietnam & $12.580,00$ & $22.511,70$ & $22.826,30$ & $27.040,00$ & $29.824,85$ \\
ASEAN & $\mathbf{3 1 9 . 2 0 0 , 4 0}$ & $\mathbf{3 3 7 . 2 8 6 , 0 9}$ & $\mathbf{3 7 0 . 4 7 8 , 2 2}$ & $\mathbf{4 2 8 . 5 3 7 , 9 2}$ & $\mathbf{4 4 4 . 7 7 9 , 0 9}$ \\
\hline
\end{tabular}

Sumber : ASEANStats

Melalui data nilai ekspor sektor jasa negara ASEAN, dapat diketahui bahwa ekspor sektor jasa ASEAN berpotensi untuk ditingkatkan lagi nilai tambah ekspornya. Hal ini didukung pula dengan adanya AFAS sebagai wadah untuk meningkatkan dan mengembangkan perdagangan jasa, termasuk di dalamnya adalah ekspor sektor jasa.

Sejak Paket AFAS ke-10 disahkan, Negara Anggota ASEAN telah berkomitmen untuk membuka pasar jasa satu sama lain di semua sektor jasa dan subsektor jasa. Terlebih Dewan Mayarakat Ekonomi ASEAN (MEA) mengamanatkan peninjauan dan penyempurnaan AFAS menjadi kesepakatan yang komprehensif. ASEAN kemudian sepakat bahwa AFAS ditingkatkan menjadi ASEAN Trade in Services Agreement (ATISA). Komitmen ATISA diadopsi dari komitmen AFAS Paket ke-10, dimana integrasi ekonomi ASEAN tersebut berpedoman pada Cetak Biru Masyarakat Ekonomi ASEAN (MEA) 2025 yang diadopsi dari Cetak Masyarakat Ekonomi ASEAN (MEA) sebelumnya yang ditandatangani pada November 2015 (ASEAN Secretariat, 2021).

ATISA merupakan respon ASEAN terhadap perkembangan global di bidang jasa dengan fitur-fitur yang komprehensif dan lebih baik. Perjanjian ATISA bertujuan untuk meningkatkan perdagangan jasa di ASEAN dan mengubah ASEAN menjadi ekonomi jasa yang sangat kompetitif. Perjanjian ATISA akan memperdalam integrasi sektor jasa dan menciptakan perdagangan yang lebih bebas, stabil, dan dapat diprediksi untuk penyedia jasa di wilayah ASEAN (ASEAN, 2020).

Merujuk pada pustaka yang telah ada, secara umum daya saing merupakan keterampilan atau kinerja suatu sektor dalam menempuh pasar internasional dan keterampilan agar mampu bertahan di dalam pasar tersebut (Wardani \& Mulatsih, 2017). Daya saing dapat diukur menggunakan indikator keunggulan komparatif dan keunggulan kompetitif. Keunggulan komparatif (comparative advantage) menurut Tarigan merupakan aktivitas ekonomi yang lebih memberikan keuntungan untuk pengembangan suatu daerah (Kementerian Riset dan Teknologi, 2020). Taringan menyampaikan lebih lanjut bahwa keunggulan komparatif diperkenalkan pada tahun 1917 oleh David Ricardo dimana ia berpendapat bahwa apabila terjadi kegiatan perdagangan antara dua negara dimana negara yang melakukan perdagangan tersebut memfokuskan melakukan penjualan atau ekspor yang dirasa memiliki keunggulan, maka dapat 
diartikan bahwa kedua negara tersebut nantinya akan mendapat keuntungan. Sedangkan keunggulan kompetitif (competitive advantage) merupakan kemampuan daya saing suatu daerah dengan daerah lainnya yang berhubungan dengan kegiatan perekonomian. Keunggulan kompetitif dapat memperlihatkan kapasitas daerah dalam menjual produknya ke luar daerah (Kementerian Riset dan Teknologi, 2020).

Berdasarkan teori, ekspor menurut Undang-Undang RI Nomor. 7 Tahun 2014 Tentang Perdagangan merupakan suatu aktivitas mengeluarkan barang dari wilayah negara atau Daerah Pabean (Republik Indonesia, 2014). Dalam penelitian yang dilakukan oleh Nopriyandi \& Haryadi (2017) menyatakan bahwa ekspor merupakan aktivitas memasarkan produk baik barang ataupun jasa kepada masyarakat negara lain. Menurut Epaphra ekspor dapat menjadikan suatu negara baik negara miskin maupun berkembang untuk memperluas jangkauan pasar mereka melalui keuntungan yang didapatkan, yaitu menghasilkan devisa negara, menambah kapasitas produksi, dan membantu dalam penyerapan tenaga kerja dimana hal tersebut akan berpengaruh terhadap petumbuhan ekonomi negara terkait (Warni \& Setyari, 2019). Model basis ekspor diperkenalkan oleh Douglas C. North tahun 1955 dimana ia menunjukkan bahwa perkembangan ekonomi di suatu wilayah mengacu pada seberapa besar taksiran keunggulan kompetitif yang terdapat di wilayah tersebut (Sjafrizal, 2018). Peraturan Menteri Keuangan Nomor 32 Tahun 2019 Pasal 3 menyebutkan bahwa Ekspor Jasa Kena Pajak adalah aktivitas pelayanan di dalam Daerah Pabean yang mengakibatkan suatu barang, fasilitas, kemudahan, atau hak tersedia untuk dimanfaatkan di luar Daerah Pabean (Menteri Keuangan Republik Indonesia, 2019).

Lebih lanjut, secara teoretis, Adrian Payne menyampaikan pendapatnya terkait perdagangan jasa, dimana perdagangan jasa ialah aktivitas atau kegiatan ekonomi yang bernilai dan memiliki manfaat intangible atau manfaat yang tidak berwujud dimana dibutuhkan sejumlah hubungan dengan pembeli atau dengan sumber daya fisik terkait, namun tidak terjadi perpindahan kepemilikan (Kementerian Perdagangan Republik Indonesia, 2015). Menurut Undang-Undang RI Nomor 7 Tahun 2014 Tentang Perdagangan, jasa merupakan setiap fasilitas yang berupa tindakan atau hasil kerja yang diraih yang dipasarkan dalam masyarakat agar dapat dikonsumsi oleh pembeli atau pelaku usaha (Republik Indonesia, 2014). IMF telah mengeluarkan Balance of Payments and Internationaal Investment Position Manual Sixth Edition (BPM6) atau Pedoman Neraca Pembayaran dan Investasi Internasional Edisi Ke-6. Diberlakukannya BPM6, membuat adanya beberapa perubahan khususnya pada perdagangan jasa. WTO menetapkan jasa yang masuk dalam data BPM6 menjadi 12 kategori utama, yaitu jasa manufaktur pada input fisik yang dimiliki oleh orang lain; jasa transportasi; jasa pemeliharaan dan perbaikan; jasa perjalanan; jasa konstruksi; jasa asuransi dan pensiun; jasa biaya untuk penggunaan kekayaan intelektual; jasa keuangan; jasa telekomunikasi, komputer, dan layanan informasi; jasa pribadi, budaya, dan rekreasi; jasa bisnis lainnya; serta jasa pemerintah (Trade Map, 2019).

Penelitian terkait daya saing sektor jasa pernah dilakukan sebelumnya oleh Fajarin (2020) dengan judul Analisis Daya Saing Sektor Pariwisata Kabupaten Banyuwangi : Pendekatan Competitiveness Monitor dan Porter's Diamond. Hasil analisis Competitiveness Monitor menyatakan bahwa semua indikator terletak di posisi yang lebih tinggi dibanding dengan beberapa kabupaten se-Eks Karesidenan Besuki, indikator pengembangan infrastruktur mempunyai tren yang negatif, serta indeks komposit indikator sosial mempunyai nilai terkecil dibanding indikator lainnya. Sementara analisis Porter's Diamond menunjukkan bahwa sektor pariwisata Kabupaten Banyuwangi memiliki daya saing yang sangat baik bila dibandingkan dengan daerah pembandingnya. 


\section{6 | Bina Ekonomi}

Penelitian tentang daya saing sektor jasa khususnya jasa keuangan juga pernah dilakukan sebelumnya oleh Rakhmat (2020) yang berjudul Analisis Daya Saing Antara Bank BUMN dengan Bank Non BUMN Indonesia. Penelitian ini menggunakan alat analisis Revealed Comparative Advantage (RCA). Hasil RCA menunjukkan bahwa Bank BNI merupakan bank dengan keunggulan komparatif tertinggi di sektor pendapatan operasional dibandingkan dengan bank lainnya, sementara bank BTN mempunyai keunggulan komparatif tertinggi di sektor pendapatan bunga dibandingkan dengan bank lainnya. Dapat disimpulkan bahwa kondisi keuangan kelompok Bank BUMN lebih baik daripada kelompok Bank Non BUMN.

Penelitian juga dilakukan pula oleh Setiawan (2013) dengan judul Prospek dan Daya Saing Sektor Perasuransian Indonesia Di Tengah Tantangan Integrasi Jasa Keuangan ASEAN. Penelitian dilakukan dengan menggunakan pendekatan deskriptif komparatif. Hasil menunjukkan berdasarkan ukuran penetration rate dan density rate, dalam kelompok negara ASEAN-4, menunjukkan bahwa sektor perasuransian Indonesia masih tertinggal dimana posisi Indonesia berada di bawah Singapura dan Malaysia. Namun Indonesia masih memiliki peluang untuk menjadi industri perasuransian yang leading di Kawasan ASEAN dimana dengan catatan mendapat dukungan kebijakan yang kondusif bagi pertumbuhannya.

Maulana \& Kartiasih (2017) melakukan penelitian berjudul Analisis Ekspor Kakao Olahan Indonesia ke Sembilan Negara Tujuan Tahun 2000-2014. Analisis yang digunakan adalah RCA dan regresi data panel. Analisis RCA menyatakan keunggulan komparatif tinggi dimiliki oleh kakao olahan Indonesia di Spanyol, namun memiliki keunggulan komparatif rendah di Singapura. Sementara perhitungan regresi data panel memperlihatkan PDB, populasi, RCA, dan kebijakan bea keluar memiliki pengaruh positif atas volume ekspor kakao, sementara harga kakao olahan berpengaruh negatif atas volume ekspor kakao.

Penelitian tentang daya saing ekspor juga dilakukan Isventina et al. (2015) dengan judul Analisis Daya Saing Sektor Industri Prioritas Indonesia dalam Menghadapi Pasar ASEAN. Penelitian ini menggunakan alat analisis RCA, dimana hasil menunjukkan bahwa industri tekstil; industri makanan dan minuman; industri pakaian jadi; industri logam dasar; dan industri kulit dan barang dari kulit memiliki daya saing tinggi yang dapat dijadikan sebagai sektor industri prioritas Indonesia.

Kerja sama perdagangan jasa yang tengah dijalin negara-negara bagian ASEAN dalam perjanjian ATISA merupakan bentuk implikasi dari Pilar Masyarakat Ekonomi ASEAN (MEA). Pilar MEA tercantum dalam dokumen Blueprint atau Cetak Biru MEA 2015 dimana terkandung empat pilar, diantaranya adalah penciptaan pasar dan basis produksi tunggal, kawasan ekonomi berdaya saing tinggi, pembangunan ekonomi yang merata dan berkelanjutan, serta kawasan yang terintegrasi dengan ekonomi global (Sekretariat Nasional ASEAN - Indonesia, 2017). MEA dibentuk bertujuan untuk mencapai integrasi ekonomi regional bagi seluruh elemen masyarakat ASEAN dalam menghadapai perdagangan bebas antarsesama negara anggota ASEAN.

Diberlakukannya MEA mengharuskan setiap Negara Anggota ASEAN bersiap untuk bersaing satu sama lain, utamanya dalam perdagangan jasa, khususnya pada kegiatan ekspor. Hal ini juga tak terlepas dari tujuan dibentuknya MEA dimana dalam salah satu pilar MEA disebutkan bahwa ASEAN memiliki misi menjelma menjadi kawasan berdaya saing ekonomi tinggi. Disamping itu, ekspor merupakan kegiatan perdagangan yang mana berperan pula dalam peningkatkan ekonomi suatu negara, sehingga sangat perlu dilakukan kajian tentang sektorsektor yang berpotensi menjadi ekspor unggulan bagi tiap negara di Kawasan ASEAN khususnya sektor jasa. Untuk melihat sejauh mana tingkat persaingan ekspor sektor jasa negara-negara 
ASEAN di kawasan ASEAN, maka perlu dilakukan analisis daya saing.

\section{METODE DAN DATA}

Pendekatan pada penelitian Analisis Daya Saing Ekspor Sektor Jasa Negara ASEAN ini adalah pendekatan kuantitatif deskriptif. Populasi penelitian ini adalah semua negara anggota ASEAN yang melakukan ekspor sektor jasa menurut Balance of Payments and Internationaal Investment Position Manual Sixth Edition (BPM6). Sampel dalam penelitian ini adalah anggota ASEAN yang melakukan ekspor 12 (dua belas) sektor jasa menurut BPM6, yaitu Indonesia, Malaysia, Filipina, Singapura, dan Vietnam.

Penelitian Analisis Daya Saing Ekspor Sektor Jasa Negara ASEAN menggunakan jenis data sekunder. Penghimpunan data dilakukan dengan metode studi kepustakaan atau dokumentasi. Data mengenai perdagangan jasa ASEAN diperoleh dari ASEANStats, data Produk Domestik Bruto (PDB) Harga Konstan 2010 diperoleh dari World Bank, dan data total ekspor diperoleh dari World Bank dan GlobalEdge (Michigan State University). Penelitian ini menggunakan beberapa alat analisis data, diantaranya adalah analisis Tipologi Klassen, Location Quotient (LQ), Revealed Comparative Advantage (RCA), dan Overlay.

\subsection{Tipologi Klassen}

Tipologi klassen adalah metode yang difungsikan untuk menandai suatu sektor atau komoditi yang memiliki keunggulan dengan membandingkan peran sektor di suatu wilayah dengan peran sektor di wilayah dengan tingkat yang lebih tinggi (Destiningsih et al., 2019). Klasifikasi tipologi klassen ada 4 (empat) kuadran, sebagai berikut :

Tabel 2. Klasifikasi Tipolofi Klassen

\begin{tabular}{|c|c|c|}
\hline & $\mathbf{y i}>\mathbf{y}$ & $\mathbf{y i}<\mathbf{y}$ \\
\hline $\mathbf{r i}>\mathbf{r}$ & Kuadran I & Kuadran II \\
& Sektor maju dan cepat tumbuh & Sektor maju tapi tertekan \\
\hline $\mathbf{r i}<\mathbf{r}$ & Kuadran III & Kuadran IV \\
& Sektor berkembang cepat & Sektor relatif tertinggal \\
\hline
\end{tabular}

Keterangan :

$\mathrm{y}=$ Kontribusi sektor terhadap PDB wilayah referensi

$r$ = Laju pertumbuhan sektor pada PDB wilayah referensi

yi = Kontribusi sektor terhadap PDB suatu negara

ri = Laju pertumbuhan sektor pada PDB suatu negara

Analisis Tipologi Klassen dilakukan melalui perhitungan perbandingan antara tingkat pertumbuhan sektor-sektor jasa Negara Anggota ASEAN dengan sektor-sektor jasa yang serupa di tingkat ASEAN. Selain itu juga dilakukan perbandingan antara tingkat 
78 | Bina Ekonomi

kontribusi sektor-sektor jasa terhadap PDB Negara Anggota ASEAN dengan sektor-sektor jasa yang serupa di tingkat ASEAN.

\subsection{Analisis LQ}

Location Quotient (LQ) merupakan koefisien yang memperlihatkan tingkat keuntungan komperatif suatu sektor, subsektor, ataupun komoditi pada suatu wilayah tertentu (Sjafrizal, 2018). Analisis LQ menjadi alat analisis yang sering digunakan sebagai rujukan dalam penelitian dengan model ekonomi basis. Secara umum, analisis ini merupakan analisis yang berguna untuk menguraikan sektor atau subsektor basis atau unggulan dalam perekonomian suatu wilayah. Hasil LQ diperoleh dari perhitungan rasio antara nilai produksi sektor i di suatu wilayah terhadap total PDB wilayah tersebut dengan rasio nilai produksi sektor i di wilayah yang lebih luas terhadap total PDB wilayah yang lebih luas tersebut.

Formula Location Quotient dirumuskan sebagai berikut:

$$
\mathrm{LQ}=\frac{v i j / v j}{V i w / V w}
$$

Keterangan :

$$
\begin{array}{ll}
v i j & =\text { Nilai produksi jasa i negara } \mathrm{j} \\
v j & =\text { Total PDB negara } \mathrm{j} \\
V i w & =\text { Nilai produksi jasa i wilayah referensi } \\
V w & =\text { Total PDB wilayah referensi }
\end{array}
$$

Hasil perhitungan LQ memiliki arti ekonomis yaitu sebagai berikut :

1) LQ > 1, menandakan sektor yang diteliti tergolong sektor basis.

2) $L Q=1$, menandakan sektor yang diteliti tergolong sektor non basis.

3) $\mathrm{LQ}<1$, menandakan sektor yang diteliti tergolong sektor non basis.

\subsection{Analisis RCA}

Revealed Competitive Advantage (RCA) merupakan konsep yang dikembangkan pada tahun 1965 oleh Bela Balassa. RCA telah banyak digunakan dalam penelitian dimana konsep ini dapat menggambarkan spesialisasi ekspor produk tertentu suatu negara. Analisis RCA digunakan untuk mengetahui kemampuan ekspor produk, baik barang maupun jasa suatu negara. Hasil RCA didapat dari hasil merasio nilai ekspor produk suatu negara terhadap total ekspor negara tersebut kemudian dibandingkan dengan nilai ekspor produk wilayah yang dijadikan referensi terhadap total ekspor wilayah yang dijadikan referensi tersebut (Isventina et al., 2015).

Secara matematis, RCA dapat ditulis dalam rumus sebagai berikut :

$$
\mathrm{RCA}=\frac{X i j / X j}{X i w / X w}
$$

Keterangan : 


$$
\begin{array}{ll}
\mathrm{Xij} & =\text { Nilai ekspor jasa } \mathrm{i} \text { negera } \mathrm{j} \\
\mathrm{Xj} & =\text { Total ekspor negara } \mathrm{j} \\
\mathrm{Xiw} & \quad=\text { Nilai ekspor jasa } \mathrm{i} \text { wilayah referensi } \\
\mathrm{Xw} & =\text { Total ekspor wilayah referensi }
\end{array}
$$

Suatu negara dikatakan sebagai negara dengan keunggulan komparatif atas suatu produk dapat dilihat dari nilai indeks RCA. Apabila hasil RCA lebih dari 1 (satu), artinya produk yang diteliti memiliki keunggulan komparatif. Sebaliknya, apabila hasil RCA kurang dari 1 (satu), artinya produk yang diteliti tidak memiliki keunggulan komparatif.

\subsection{Analisis Overlay}

Analisis Overlay merupakan telaah untuk menentukan daya saing ekspor dengan cara menggabungkan alat analisis yang digunakan, dimana dilakukan dengan memberi penilaian positif (+) dan negatif (-) pada suatu sektor (Widyaningrum \& Cahyono, 2020). Dalam penelitian ini, analisis Overlay akan menggabungkan hasil analisis Tipologi Klassen, LQ, dan RCA.

Analisis Overlay memiliki tiga kriteria, yaitu :

a. Apabila bernilai positif $(+++)$, artinya sektor yang diteliti mempunyai daya saing ekspor dibandinkan sektor sejenis di kawasan ASEAN.

b. Apabila bernilai positif $(++)$, maka sektor tersebut berpeluang menjadi sektor berdaya saing ekspor di kawasan ASEAN.

c. Apabila bernilai negatif (- - -), maka sektor yang diteliti kurang mempunyai daya saing ekspor dibandingkan sektor sejenis di kawasan ASEAN.

\section{PEMBAHASAN}

\subsection{Potensi Daya Saing Ekspor Jasa Bedasarkan Analisis Tipologi Klassen}

Hasil analisis Tipologi Klassen pada Tabel 3 menunjukkan bahwa semua negara ASEAN memiliki jasa yang termasuk kategori sektor yang cepat maju dan tumbuh cepat (kuadran I) kecuali Indonesia. Malaysia dan Filipina memiliki satu jasa yang termasuk kuadran I yaitu jasa pribadi, budaya, dan rekreasi; dan jasa telekomunikasi, komputer, dan layanan informasi. Singapura menjadi negara dengan bidang jasa paling banyak di kuadran I dimana terdapat lima jasa yaitu jasa konstruksi; jasa asuransi dan pensiun; jasa biaya untuk penggunaan kekayaan intelektual; jasa telekomunikasi, komputer, dan layanan informasi; dan jasa bisnis lainnya. Sedangkan Vietnam memiliki tiga jasa yang maju dan tumbuh pesat diantaranya adalah jasa perjalanan; jasa konstruksi; dan jasa pemerintah.

Tabel 3. Hasil Analisis Tipologi Klassen Ekspor Jasa Negara ASEAN ke Negara-Negara Tujuan Tahun 2015-2019

\begin{tabular}{|c|c|c|}
\hline $\begin{array}{c}\text { Rerata Laju Pertumbuhan } \\
\text { Ekspor Sektor Jasa (r) }\end{array}$ & \multicolumn{2}{|c|}{ Rerata Kontribusi Ekspor Sektor Jasa Terhadap PDB (y) } \\
\cline { 2 - 3 } & \multicolumn{1}{|c|}{$\mathbf{y i}$} & $\mathbf{y i}<\mathbf{y}$ \\
\hline $\mathbf{r i}>\mathbf{r}$ & IDN $:-$ & IDN $\quad:$ B, D, E, F, G, H, K \\
\hline
\end{tabular}




\begin{tabular}{|c|c|c|}
\hline & MYS : K & MYS : B, G, H \\
\hline & PHL : I & PHL : B, C, D, E, G, H, L \\
\hline & SGP $:$ E, F, H, I, J & SGP :- \\
\hline & VNM : D, E, L & VNM : B, C, G, I, J, K \\
\hline \multirow{5}{*}{$\mathbf{r i}<\mathbf{r}$} & IDN :- & IDN $: \mathrm{A}, \mathrm{C}, \mathrm{I}, \mathrm{J}, \mathrm{L}$ \\
\hline & MYS : A, D, E & MYS $:$ C, F, I, J, L \\
\hline & PHL : A, J & PHL $: \mathrm{F}, \mathrm{K}$ \\
\hline & SGP : B, C, D, G, K, L & SGP : A \\
\hline & VNM : A & VNM : F, H \\
\hline
\end{tabular}

Sumber : World Bank dan ASEANStats, diolah Penulis

Keterangan : $\mathrm{A}=$ Jasa manufaktur pada input fisik yang dimiliki oleh orang lain; B = Jasa pemeliharaan dan perbaikan; $\mathrm{C}=$ Jasa transportasi; $\mathrm{D}=$ Jasa perjalanan; $\mathrm{E}=$ Jasa konstruksi; $F$ = Jasa asuransi dan pensiun; $G$ = Jasa keuangan; $H$ = Jasa biaya untuk penggunaan kekayaan intelektual; I = Jasa telekomunikasi, komputer, dan layanan informasi; J = Jasa bisnis lainnya; $\mathrm{K}$ = Jasa pribadi, budaya, dan rekreasi; $\mathrm{L}$ = Jasa pemerintah

Disamping itu, masing banyak sektor jasa yang masuk dalam kategori sektor relatif tertinggal (kuadran IV), utamanya adalah Indonesia dan Malaysia. Kedua negara tersebut memiliki lima jasa yang tergolong pada kuadran IV, empat jasa diantaranya merupakan jasa yang sama yaitu jasa transportasi; jasa telekomunikasi, komputer, dan layanan informasi; jasa bisnis lainnya; dan jasa pemerintah, sementara sektor lainnya masing-masing adalah jasa manufatur pada input fisik yang dimiliki orang lain; dan jasa asuransi dan pensiun. Filipina dan Vietnam memiliki dua sektor jasa yang masuk kategori sektor relatif tertinggal, dimana satu sektor yang sama yaitu jasa asuransi dan pensiun, sementara sektor lainnya masing-masing adalah jasa pribadi, budaya, dan rekreasi dan jasa biaya untuk penggunaan kekayaan intelektual. Singapura merupakan negara dengan sektor jasa relatif tertinggal paling sedikit di ASEAN, dimana hanya terdapat satu sektor jasa yaitu jasa manufaktur pada input fisik yang dimiliki oleh orang lain.

\subsection{Potensi Daya Saing Ekspor Jasa Bedasarkan Analisis LQ}

Berdasarkan perhitungan LQ pada Tabel 4, hasil analisis LQ menunjukkan bahwa Indonesia tidak memiliki ekspor sektor jasa unggulan karena nilai rata-rata LQ lebih kecil dari satu (LQ > 1). Malaysia memiliki empat ekspor sektor jasa unggulan yaitu jasa manufaktur pada input fisik yang dimiliki oleh orang lain; jasa perjalanan; jasa konstruksi; dan jasa pribadi, budaya, dan rekreasi. Filipina dan Vietnam masing-masing memiliki tiga ekspor sektor jasa unggulan. Ekspor sektor jasa unggulan Filipina yaitu jasa manufaktur pada input fisik yang dimiliki oleh orang lain, jasa telekomunikasi, komputer, dan layanan informasi; dan jasa bisnis lainnya. Sedangkan ekspor sektor jasa unggulan Vietnam adalah jasa manufaktur pada input fisik yang dimiliki oleh orang lain, jasa perjalanan; dan jasa pemerintah. Sementara Singapura menjadi negara yang hampir semua sektor jasanya merupakan ekspor sektor jasa unggulan, kecuali jasa manufaktur pada input fisik yang dimiliki oleh orang lain.

Tabel 4. Nilai Rata-Rata LQ Ekspor Jasa Negara ASEAN ke Negara-Negara Tujuan Tahun 2015-2019 


\begin{tabular}{|l|c|c|c|c|c|}
\hline \multirow{2}{*}{ Sektor Jasa } & \multicolumn{5}{c|}{ Negara } \\
\cline { 2 - 6 } & Indonesia & Malaysia & Filipina & Singapura & Vietnam \\
\hline $\begin{array}{l}\text { Jasa manufaktur pada input fisik } \\
\text { yang dimiliki oleh orang lain }\end{array}$ & 0,11 & 2,13 & 1,53 & 0,25 & 6,81 \\
\hline Jasa pemeliharaan dan perbaikan & 0,09 & 0,44 & 0,10 & 7,77 & 0,06 \\
\hline Jasa transportasi & 0,13 & 0,50 & 0,29 & 6,16 & 0,71 \\
\hline Jasa perjalanan & 0,28 & 1,16 & 0,49 & 1,35 & 1,18 \\
\hline Jasa konstruksi & 0,31 & 2,27 & 0,18 & 2,84 & 0,97 \\
\hline Jasa asuransi dan pension & 0,05 & 0,45 & 0,14 & 7,75 & 0,16 \\
\hline Jasa keuangan & 0,04 & 0,15 & 0,11 & 8,11 & 0,09 \\
\hline $\begin{array}{l}\text { Jasa biaya untuk penggunaan } \\
\text { kekayaan intelektual }\end{array}$ & 0,02 & 0,18 & 0,02 & 8,37 & 0,01 \\
\hline $\begin{array}{l}\text { Jasa telekomunikasi, komputer, } \\
\text { dan layanan informasi }\end{array}$ & 0,12 & 0,93 & 2,01 & 4,75 & 0,35 \\
\hline Jasa bisnis lainnya & 0,17 & 0,55 & 1,67 & 4,62 & 0,36 \\
\hline $\begin{array}{l}\text { Jasa pribadi, budaya, dan } \\
\text { rekreasi }\end{array}$ & 0,29 & 2,25 & 0,94 & 3,49 & 0,11 \\
\hline Jasa pemerintah & 0,91 & 0,35 & 0,08 & 1,35 & 1,32 \\
\hline
\end{tabular}

Sumber : ASEANStats dan World Bank, diolah Penulis

\subsection{Potensi Daya Saing Ekspor Jasa Berdasarkan Analisis RCA}

Berdasarkan Tabel 5 dapat diketahui dalam periode 2015-2019, Indonesia memiliki dua ekspor sektor jasa yang memiliki keunggulan komparatif yaitu jasa konstruksi dan jasa pemerintah. Malaysia sendiri memiliki ekspor sektor jasa yang memiliki keunggulan komparatif lebih banyak dibandingkan dengan Indonesia, antara lain jasa manufaktur pada pada input fisik yang dimiliki oleh orang lain; jasa perjalanan; jasa konstruksi; dan jasa pribadi, budaya, dan rekreasi.

Kemudian Filipina memiliki jasa manufaktur pada input fisik yang dimiliki oleh orang lain; jasa perjalanan; jasa telekomunikasi, komputer, dan layanan informasi; jasa bisnis lainnya; dan jasa pribasi, budaya, dan rekreasi sebagai ekspor sektor jasa yang memiliki keunggulan komparatif. Ekspor sektor jasa Singapura yang memiliki keunggulan komparatif adalah jasa pemeliharaan dan perbaikan; jasa transportasi; jasa asuransi dan pension; jasa keuangan; jasa biaya untuk penggunaan kekayaan intelektual; jasa telekomunikasi, komputer, dan layanan informasi; jasa bisnis lainnya; dan jasa pribadi, budaya, dan rekreasi. Sementara ekspor sektor jasa Vietnam yang memiliki keunggulan komparatif adalah jasa manufaktur pada input fisik yang dimiliki oleh orang lain; jasa asuransi dan pensiun; jasa telekomunikasi, komputer, dan layanan informasi; jasa bisnis lainnya; jasa pribadi, budaya, dan rekreasi; dan jasa pemerintah.

Tabel 5. Nilai Rata-Rata Ekspor Jasa Negara ASEAN ke Negara-Negara Tujuan Tahun 2015-2019

\begin{tabular}{|l|c|c|c|c|c|}
\hline \multicolumn{1}{|c|}{ Sektor Jasa } & \multicolumn{5}{|c|}{ Negara } \\
\cline { 2 - 6 } & Indonesia & Malaysia & Filipina & Singapura & Vietnam \\
\hline $\begin{array}{l}\text { Jasa manufaktur pada input fisik } \\
\text { yang dimiliki oleh orang lain }\end{array}$ & 0,37 & 2,00 & 3,46 & 0,08 & 1,48 \\
\hline $\begin{array}{l}\text { Jasa pemeliharaan dan } \\
\text { perbaikan }\end{array}$ & 0,32 & 0,42 & 0,22 & 2,46 & 0,86 \\
\hline
\end{tabular}




\begin{tabular}{|l|c|c|c|c|c|}
\hline Jasa transportasi & 0,44 & 0,47 & 0,65 & 1,95 & 0,88 \\
\hline Jasa perjalanan & 0,95 & 1,11 & 1,10 & 0,43 & 0,90 \\
\hline Jasa konstruksi & 1,06 & 2,16 & 0,41 & 0,90 & 1,13 \\
\hline Jasa asuransi dan pension & 0,15 & 0,43 & 0,32 & 2,46 & 0,84 \\
\hline Jasa keuangan & 0,14 & 0,14 & 0,24 & 2,57 & 0,77 \\
\hline $\begin{array}{l}\text { Jasa biaya untuk penggunaan } \\
\text { kekayaan intelektual }\end{array}$ & 0,08 & 0,17 & 0,05 & 2,65 & 0,74 \\
\hline $\begin{array}{l}\text { Jasa telekomunikasi, komputer, } \\
\text { dan layanan informasi }\end{array}$ & 0,42 & 0,89 & 4,53 & 1,50 & 1,84 \\
\hline Jasa bisnis lainnya & 0,58 & 0,52 & 3,76 & 1,46 & 1,58 \\
\hline $\begin{array}{l}\text { Jasa pribadi, budaya, dan } \\
\text { rekreasi }\end{array}$ & 0,98 & 2,16 & 2,11 & 1,11 & 1,59 \\
\hline Jasa pemerintah & 3,09 & 0,34 & 0,19 & 0,43 & 1,01 \\
\hline
\end{tabular}

Sumber : ASEANStats, World Bank, dan GlobalEdge, diolah Penulis

\subsection{Potensi Daya Saing Ekspor Jasa Berdasarkan Analisis Overlay}

Untuk mengetahui daya saing ekspor sektor jasa Negara ASEAN dengan mengacu pada tiga alat analisis, yaitu Tipologi Klassen, LQ, dan RCA, maka dilakukan melalui perhitungan gabungan ketiga alat analisis tersebut yaitu dengan menggunakan analisis Overlay. Dengan demikian, perlu terlebih dahulu dilakukan penyamaan koefisien ketiga alat analisis, dimana koefisien positif (+) ditujukan untuk sektor jasa yang berada di kuadran I, dan jasa dengan nilai LQ serta RCA lebih dari 1, sementara koefisien negatif (-) ditujukan untuk sektor jasa yang tergolong kuadran II, III, dan IV dan jasa dengan nilai LQ serta RCA kurang dari satu.

Berdasarkan Tabel 6 menunjukkan bahwa Singapura menjadi negara dengan jasa berdaya saing ekspor paling banyak dibandingkan dengan negara ASEAN lainnya, dimana memiliki empat jasa yaitu jasa asuransi dan pensiun; jasa biaya untuk penggunaan kekayaan intelektual; jasa telekomunikasi, komputer, dan layanan informasi; dan jasa bisnis lainnya. Selain itu, banyak jasa Singapura yang berpeluang menjadi sektor jasa yang berdaya saing ekspor, antara lain jasa pemeliharaan dan perbaikan; jasa transportasi; jasa konstruksi; jasa keuangan; dan jasa pribadi, budaya, dan rekreasi. Malaysia memiliki jasa pribadi, budaya, dan rekreasi sebagai jasa yang berdaya saing ekspor di kawasan ASEAN. Terdapat beberapa jasa yang berpeluang menjadi sektor jasa berdaya saing ekspor yaitu jasa manufaktur pada input fisik yang dimiliki oleh orang lain; jasa perjalanan; dan jasa konstruksi.

Tabel 6. Hasil Analisis Overlay

\begin{tabular}{|c|c|c|c|c|c|c|c|c|c|c|c|c|c|c|c|}
\hline \multirow{2}{*}{$\begin{array}{c}\text { Sektor } \\
\text { Jasa }\end{array}$} & \multicolumn{3}{|c|}{ Indonesia } & \multicolumn{3}{|c|}{ Malaysia } & \multicolumn{3}{|c|}{ Filipina } & \multicolumn{3}{|c|}{ Singapura } & \multicolumn{3}{|c|}{ Vietnam } \\
\hline & TK & LQ & RCA & TK & LQ & RCA & TK & LQ & RCA & TK & LQ & RCA & TK & LQ & RCA \\
\hline A & - & - & - & - & + & + & - & + & + & - & - & - & - & + & + \\
\hline B & - & - & - & - & - & - & - & - & - & - & + & + & - & - & - \\
\hline $\mathrm{C}$ & - & - & - & - & - & - & - & - & - & - & + & + & - & - & - \\
\hline $\mathrm{D}$ & - & - & - & - & + & + & - & - & + & - & + & - & + & + & - \\
\hline$E$ & - & - & + & - & + & + & - & - & - & + & + & - & + & - & - \\
\hline$F$ & - & - & - & - & - & - & - & - & - & + & + & + & - & - & - \\
\hline G & - & - & - & - & - & - & - & - & - & - & + & + & - & - & - \\
\hline $\mathrm{H}$ & - & - & - & - & - & - & - & - & - & + & + & + & - & - & - \\
\hline
\end{tabular}


Volume 24 No 1 Tahun 2020 | 83

\begin{tabular}{|c|c|c|c|c|c|c|c|c|c|c|c|c|c|c|c|}
\hline I & - & - & - & - & - & - & + & + & + & + & + & + & - & - & - \\
\hline $\mathrm{J}$ & - & - & - & - & - & - & - & + & + & + & + & + & - & - & - \\
\hline $\mathrm{K}$ & - & - & - & + & + & + & - & - & + & - & + & + & - & - & - \\
\hline $\mathrm{L}$ & - & - & + & - & - & - & - & - & - & - & + & - & + & + & - \\
\hline & \multicolumn{3}{|c|}{ - } & \multicolumn{3}{|c|}{$\mathbf{K}$} & \multicolumn{3}{|c|}{ I } & \multicolumn{3}{|c|}{ F, H, I, dan J } & \multicolumn{3}{|c|}{ - } \\
\hline
\end{tabular}

Keterangan : $\mathrm{A}=$ Jasa manufaktur pada input fisik yang dimiliki oleh orang lain; B = Jasa pemeliharaan dan perbaikan; $\mathrm{C}=$ Jasa transportasi; $\mathrm{D}=$ Jasa perjalanan; $\mathrm{E}=$ Jasa konstruksi; F = Jasa asuransi dan pensiun; $\mathrm{G}$ = Jasa keuangan; $\mathrm{H}$ = Jasa biaya untuk penggunaan kekayaan intelektual; I = Jasa telekomunikasi, komputer, dan layanan informasi; J = Jasa bisnis lainnya; $\mathrm{K}$ = Jasa pribadi, budaya, dan rekreasi; $\mathrm{L}=$ Jasa pemerintah

Sementara itu, daya saing ekpsor jasa yang dimiliki Filipina sendiri yaitu jasa telekomunikasi, komputer, dan layanan informasi. Filipina juga memiliki jasa yang berpeluang menjadi sektor jasa berdaya saing ekspor, antara lain jasa manufaktur pada input fisik yang dimiliki oleh orang lain; dan jasa bisnis lainnya. Indonesia dan Vietnam tidak memiliki jasa yang berdaya saing ekspor. Berbeda dengan Indonesia, Vietnam memiliki jasa yang berpeluang menjadi sektor jasa berdaya saing ekspor dengan memiliki koefisien positif berjumlah dua $(++)$, yaitu jasa manufaktur pada input fisik yang dimiliki oleh orang lain; jasa perjalanan; dan jasa pemerintah.

\section{SIMPULAN}

Merujuk pada hasil perhitungan dengan menggunakan tiga alat analisis yaitu Tipologi Klassen, LQ, dan RCA yang ditunjukkan pada hasil analisis Overlay, maka dapat disimpulkan bahwa daya saing ekspor sektor jasa yang dimiliki Singapura adalah jasa asuransi dan pensiun; jasa biaya untuk penggunaan kekayaan intelektual; jasa telekomunikasi, komputer, dan layanan informasi; dan jasa bisnis lainnya. Daya saing ekspor sektor jasa yang dimiliki Malaysia yaitu jasa pribadi, budaya, dan rekreasi, sedangkan Filipina adalah jasa telekomunikasi, komputer, dan layanan informasi. Sementara itu, Indonesia dan Vietnam merupakan negara ASEAN yang tidak memiliki sektor jasa yang berdaya saing ekspor. Hal tersebut menunjukkan bahwa Singapura, Malaysia, dan Filipina merupakan Negara Anggota ASEAN yang memiliki sektor jasa unggulan pada kegiatan ekspor. Sektor-sektor jasa tersebut menjadi sektor jasa yang memiliki daya saing ekspor lebih tinggi di Kawasan ASEAN dibandingkan dengan sektor jasa sejenis yang dimiliki oleh Negara ASEAN lainnya. Dengan demikian, sektor jasa tersebut perlu dikembangkan agar nantinya dapat menciptakan nilai tambah dan memberikan kontribusi besar bagi perekonomian negara.

Meskipun hasil perhitungan secara global daya saing ekspor jasa Negara ASEAN dengan menggunakan tiga alat analisis, yaitu Tipologi Klassen, LQ, RCA, dan Overlay menyatakan Indonesia dan Vietnam tidak memiliki daya saing ekspor jasa dan masih tertinggal dengan Negara Anggota ASEAN lainnya, terutama Singapura, namun kedua negara memiliki tren perkembangan sektor jasa yang cukup positif. Dengan demikian, kedua negara pasti memiliki ekspor jasa yang diunggulkan di masing-masing negara, baik menurut besaran nilai ekspor jasa tersebut maupun besaran kontribusinya terhadap PDB negara. 


\section{4 | Bina Ekonomi}

Indonesia memiliki beberapa jasa yang menjadi unggulan dalam hal ekspor, diantaranya adalah jasa perjalanan; jasa bisnis lainnya; jasa transportasi; serta jasa telekomunikasi, komputer, dan layanan informasi. Rata-rata kontribusi jasa perjalanan Indonesia terhadap PDB Indonesia tahun 2015-2019 adalah sebesar 1,24\%, jasa bisnis lainnya sebesar 0,53\%, jasa transportasi sebesar 0,33\%, serta jasa telekomunikasi, komputer, dan layanan informasi sebesar 0,10\%. Sementara itu, Vietnam juga memiliki jasa yang menjadi unggulan bagi negaranya, yaitu jasa perjalanan; jasa manufaktur pada input fisik yang dimiliki oleh orang lain; jasa transportasi; serta jasa bisnis lainnya. Jasa-jasa tersebut merupakan jasa dengan nilai ekspor jasa dan rata-rata kontribusi yang tinggi dibandingkan dengan jasa lainnya. Jasa perjalanan memiliki rata-rata kontribusi terhadap PDB Vietnam tahun 2015-2019 sebesar 5,25\%, jasa manufaktur pada input fisik yang dimiliki oleh orang lain sebesar 3,89\%, jasa transportasi sebesar 1,84\%, serta jasa bisnis lainnya sebesar $1,13 \%$.

Upaya dalam meningkatkan daya saing ekspor jasa Negara ASEAN dapat dilakukan oleh setiap negara baik negara yang sudah memiliki banyak jasa berdaya saing tinggi maupun yang belum, khususnya Indonesia dan Vietnam. Peningkatan ekspor jasa dapat dilakukan dengan memanfaatkan kerja sama yang ada yaitu kerja sama perdagangan jasa ASEAN dengan tujuan meningkatkan nilai tambah dan kualitas produk jasa agar menjadi produk yang lebih kompetitif di pasar internasional sekaligus semakin memudahkan kegiatan perdagangan serta dapat mengurangi hambatan dalam perdagangan sektor jasa ASEAN.

Adapun beberapa saran yang Penulis dapat berikan guna meningkatkan daya saing ekspor jasa Negara ASEAN yang masih memiliki daya saing rendah khususnya Indonesia dan Vietnam, diantaranya adalah sebagai berikut :

1. Peran pemerintah dalam meningkatkan kualitas sektor jasa, salah satunya yaitu dalam hal promosi. Dengan promosi yang berkualitas maka akan menyebabkan produk-produk jasa menjadi semakin dikenal oleh masyarakat luas. Dengan memanfaatkan perkembangan teknologi di era digital ini, maka akan semakin memudahkan dalam hal promosi dengan cakupan yang lebih luas. Selain itu dengan kegiatan promosi yang dilakukan secara intens maka secara tidak langung dapat menarik minat konsumen.

2. Terjalinnya kerja sama antara masyarakat dan pemerintah. Masyarakat harus menyadari bahwa sektor jasa kini semakin memegang peranan yang penting dalam perekonomian dan memiliki potensi yang baik sehingga masyarakat harus ikut mengembangkan sektor jasa. Sementara pemerintah sendiri harus mendukung dan menopang sektor jasa negaranya dengan turut aktif dalam menjalin kerjasama perdagangan internasional khususnya bidang jasa sehingga kegiatan ekspor jasa dapat berjalan dengan mudah dan semakin bebas dari hambatan-hambatan.

3. Diharapkan pemerintah dan masyarakat tiap negara mampu menciptakan inovasi-inovasi agar daya saing sektor jasa khususnya dalam kegiatan ekspor dapat terus berkembang dengan baik secara berkelanjutan.

\section{DAFTAR PUSTAKA}

AEC Council Indonesia. (2019). Mengenal Kerangka Kerja ASEAN di Bidang Jasa (AFAS). Diunduh dari https://meaindonesia.ekon.go.id/mengenal-kerangka-kerja-asean-di-bidang-jasaafas/

ASEAN. (2020). ASEAN Signs Trade in Services Agreement. Diunduh dari https://asean.org/asean- 
signs-trade-services-agreement-2/

ASEAN Secretariat. (2021). ASEAN Integration in Services. Jakarta.

ASEANStats. (2020). ASEAN Trade in Services by Reporting Countries and Major Service Categories in US\$ Million. Diunduh dari https://data.aseanstats.org/sits-by-reporters-and-services

Cann, 0. (2016). What is competitiveness. Diunduh dari https://www.weforum.org/agenda/2016/09/what-is-competitiveness/

Destiningsih, R., Sugiharti, R. R., \& Achsa, A. (2019). Food Commodity Competitiveness and Accessibility in Barlingmascakeb. Jejak, 12(1), 218-237. doi:10.15294/jejak.v12i1.18783

Direktorat Jenderal Kerja Sama ASEAN Kementerian Luar Negeri RI. (2015). Majalah Masyarakat ASEAN Edisi 7: Membidik Peluang MEA. Direktorat Jenderal Kerja Sama ASEAN.

Fajarin, I. dan B. F. (2020). Analisis Daya Saing Sektor Pariwisata Kabupaten Banyuwangi : Pendekatan Competitiveness Monitor Dan Porter's Diamond. Jurnal Ilmiah Mahasiswa FEB, $8(2), 1-13$.

GlobalEdge. (2021). ASEAN: Introduction >> globalEDGE: Your source for Global Business Knowledge. Diunduh dari https://globaledge.msu.edu/trade-blocs/asean

Isventina, Nuryartono, N., \& Hutagaol, M. P. (2015). Analisis Daya Saing Sektor Industri Prioritas Indonesia dalam Menghadapi Pasar ASEAN. Jurnal Ekonomi Dan Kebijakan Pembangunan, 4(1), 71-93. doi:10.29244/jekp.v4i1.19924

Kementerian Perdagangan Republik Indonesia. (2015). Laporan Akhir Analisis Posisi Perdagangan Jasa Indonesia pada Perundingan ACFTA. Kementerian Perdagangan RI. Jakarta.

Kementerian Riset dan Teknologi. (2020). Panduan Indeks Daya Saing Daerah. Kementerian Riset dan Teknologi. Jakarta.

Maulana, A., \& Kartiasih, F. (2017). Analisis Ekspor Kakao Olahan Indonesia ke Sembilan Negara Tujuan Tahun 2000-2014. Jurnal Ekonomi Dan Pembangunan Indonesia, 17(2), 103-117. doi:10.21002/jepi.v17i2.664

Menteri Keuangan Republik Indonesia. (2019). Peraturan Menteri Keuangan Republik Indonesia. Jakarta.

Nopriyandi, R., \& Haryadi. (2017). Analisis Ekspor Kopi Indonesia. Jurnal Paradigma Ekonomika, 12(1), 1-10. doi:10.22437/paradigma.v12i1.3929

Rakhmat, A. S. (2020). Analisis Daya Saing Antara Bank Bumn Dengan Bank Non Bumn Indonesia. Indonesian Journal of Strategic Management, 3(1), 15-23. doi:10.25134/ijsm.v3i1.2816

Republik Indonesia. (2014). Undang-Undang Republik Indonesia Nomor 7 Tahun 2014 Tentang Perdagangan. Lembaran Negara RI Tahun 2014 No. 45. Jakarta.

Sa'idy, I. B. (2013). Analisis Daya Saing Komoditas Tekstil Dan Produk Tekstil Indonesia Di Amerika Serikat. Economics Development Analysis Journal, 2(4), 269-276. doi:10.15294/edaj.v2i4.2482

Sekretariat Nasional ASEAN - Indonesia. (2017). Pilar Masyarakat Ekonomi ASEAN (MEA). Diunduh dari http://setnas-asean.id/pilar-ekonomi

Setiawan, S. (2013). Prospek dan Daya Saing Sektor Perasuransian Indonesia Di Tengah 
86 | Bina Ekonomi

Tantangan Integrasi Jasa. Naga Media, 81-106.

Sjafrizal. (2018). Analisis Ekonomi Regional dan Penerapannya di Indonesia. Depok: Rajawali Pres.

Trade Map. (2019). Frequently Asked Questions. Diunduh dari https://www.trademap.org/stFAQ.aspx?nvpm=1\%7C\%7C\%7C\%7C\%7C\%7C\%7C\%7C\%7 C\%7C\%7C\%7C\%7C\%7C\%7C\%7C\%7C\#li_Answer5_2

Wardani, M. A., \& Mulatsih, S. (2017). Analisis Daya Saing dan Faktor-Faktor yang Memengaruhi Ekspor Ban Indonesia ke Kawasan Amerika Latin. Jurnal Ekonomi Dan Kebijakan Pembangunan, 6(1), 81-100. doi:10.29244/jekp.v6i1.22452

Warni, G. S., \& Setyari, N. P. W. (2019). Analisis Daya Saing Ekspor Pakaian Jadi Indonesia Ke Pasar Jerman Periode Tahun 2013-2018. E-Jurnal Ekonomi Pembangunan Unversitas Udayana, 8(11), 2656-2688.

Widyaningrum, E. D. A., \& Cahyono, H. (2020). Pemetaan Potensi Wilayah Guna Mendorong Pembangunan Ekonomi Kabupaten Ngawi. Jurnal Dinamika Ekonomi Pembangunan, 3(2), 117-139.

World Bank. (2020). Exports of goods and services (BoP, current US\$). Diunduh dari https://data.worldbank.org/indicator/BX.GSR.GNFS.CD

World Bank. (2021). GDP (constant 2010 US\$). Diunduh dari https://data.worldbank.org/indicator/NY.GDP.MKTP.KD 